\title{
Modelling the growth of tambaqui, Colossoma macropomum (Cuvier, 1816) in floodplain lakes: model selection and multimodel inference
}

\author{
Costa, LRF ${ }^{a *}$, Barthem, RB. ${ }^{a}$, Albernaz, AL. ${ }^{b}$, Bittencourt, MM. ${ }^{c}$ and Villacorta-Corrêa, MA. ${ }^{d}$ \\ ${ }^{a}$ Coordenação de Zoologia, Museu Paraense Emílio Goeldi - MPEG, CP 399, \\ Terra-Firme, CEP 66077-830, Belém, PA, Brazil

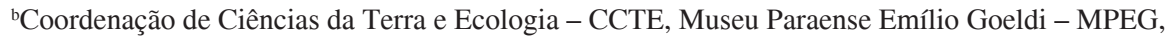 \\ Terra-Firme, CP 399, CEP 66077-830, Belém, PA, Brazil \\ ${ }^{c}$ Coordenação de Pesquisas em Biologia Aquática - CPBA, Instituto Nacional de Pesquisas da Amazônia - INPA, \\ CP 478, CEP 69011-970, Manaus, AM, Brazil \\ ${ }^{\mathrm{d} D e p a r t a m e n t o ~ d e ~ C i e ̂ n c i a s ~ P e s q u e i r a s, ~ U n i v e r s i d a d e ~ F e d e r a l ~ d a ~ A m a z o ̂ n i a ~-~ U F A M, ~}$ \\ Av. General Rodrigo Otávio Jordão Ramos, 3000, CEP 69077-000, Manaus, AM, Brazil \\ *e-mail: luizrfcosta@uol.com.br
}

Received March 26, 2012 - Accepted July 23, 2012 - Distributed May 31, 2013

(With 2 figures)

\begin{abstract}
The tambaqui, Colossoma macropomum, is one of the most commercially valuable Amazonian fish species, and in the floodplains of the region, they are caught in both rivers and lakes. Most growth studies on this species to date have adjusted only one growth model, the von Bertalanffy, without considering its possible uncertainties. In this study, four different models (von Bertalanffy, Logistic, Gompertz and the general model of Schnüte-Richards) were adjusted to a data set of fish caught within lakes from the middle Solimões River. These models were adjusted by non-linear equations, using the sample size of each age class as its weight. The adjustment evaluation of each model was based on the Akaike Information Criterion (AIC), the variation of AIC between the models $(\Delta i)$ and the evidence weights (wi). Both the Logistic $(\Delta i=0.0)$ and Gompertz $(\Delta i=1.12)$ models were supported by the data, but neither of them was clearly superior (wi, respectively 52.44 and $29.95 \%$ ). Thus, we propose the use of an averaged-model to estimate the asymptotic length $(\mathrm{L} \infty)$. The averaged-model, based on Logistic and Gompertz models, resulted in an estimate of $\mathrm{L}_{\infty}=90.36$, indicating that the tambaqui would take approximately 25 years to reach average size.
\end{abstract}

Keywords: Amazon, Colossoma macropomum, fish growth, model selection, multimodel inference.

\section{Modelagem do crescimento do tambaqui (Colossoma macropomum Cuvier, 1816): seleção de modelos e inferência multimodelos}

\begin{abstract}
Resumo
O tambaqui, Colossoma macropomum, é uma das espécies de peixes amazônicos de maior valor comercial, sendo capturado em rios e lagos da planície alagável da região. Até o presente, a maioria dos estudos sobre essa espécie tem ajustado um único modelo de crescimento, o de von Bertalanffy, sem considerer as possíveis incertezas associadas ao uso do modelo. Neste estudo, quatro modelos diferentes (von Bertalanffy, Logístico, Gompertz e o modelo geral de Schnüte-Richards) foram ajustados a um conjunto de dados de peixes capturados no interior de lagos situados no médio Solimões. Esses modelos foram ajustados por equações não lineares e o número de tambaquis em cada classe de tamanho foi usado como peso no ajuste. A avaliação do ajuste de cada modelo foi baseada no Critério de Informação de Akaike (AIC), na diferença do AIC entre os modelos $(\Delta i)$ e nos pesos de evidência (wi). Tanto o modelo Logístico $(\Delta i=0,0)$ como o de Gompertz $(\Delta i=1,12)$ foram suportados pelos dados, mas nenhum deles foi claramente superior (wi, respectivamente, de 52,44 e 29,95\%). Assim, é proposto o uso de um modelo médio para estimar o comprimento assintótico $(\mathrm{L} \infty)$. O modelo médio, baseado nos modelos Logístico e de Gompertz, resultou em uma estimativa de $\mathrm{L} \infty=90,36$ e indicou que o tambaqui levaria aproximadamente 25 anos para atingir esse tamanho.
\end{abstract}

Palavras-chave: Amazônia, Colossoma macropomum, crescimento de peixes, seleção de modelos, inferência multimodelos. 


\section{Introduction}

The tambaqui, Colossoma macropomun (Cuvier 1816, Characidae), is the largest characin of the Neotropical region. It migrates hundreds of kilometers in the rivers along the lowland Amazon basin. Juveniles feed on zooplankton in the floodplain lakes, and adults feed on fruits and seeds in the flooded forests (Araújo-Lima and Goulding, 1997; Costa et al., 1999; Goulding and Carvalho, 1982). There is one panmictic population in this region (Santos et al., 2007), with an estimated potential yield of 15,000 tons (Barthem and Goulding, 2007). Tambaquis respond strongly to fluctuations in water level, and the tambaqui fishery is influenced by these fluctuations. In the central Amazon, the tambaqui fishery exploits stocks of adult tambaquis when in dispersion or reproductive movements, and juvenile tambaquis are mostly captured in floodplain lakes during the dry season (Araújo-Lima and Goulding, 1997; Costa et al., 2001; Goulding and Carvalho, 1982). A decline in large adult tambaqui catch in the last few years has forced the commercial fleet, responsible for supplying Amazon markets, to exploit the floodplain lakes more intensively. This has resulted in an increase in juvenile and young adult catch and consequently in a diminution in the mean size of landed tambaquis (Araújo-Lima and Goulding, 1997; Costa et al., 2001; Isaac and Ruffino, 1996). Excessive tambaqui fishing has transformed this resource from underexploited in the 1970s (Petrere, 1983) to a "growth-overfishing" condition in the 1990s (Costa et al., 1999; Isaac and Ruffino, 1996).

One of the main sources of variation in stock biomass is the growth of individuals that are already in the population. Thus, studies on the growth of species of commercial value, such as Colossoma macropomum, are very important to fishery management strategies. To date, published studies on tambaqui growth have been conducted based on the arbitrary choice of a single model (usually the von Bertalanffy equation), and the parameter estimation and inference of growth are based on this unique model adjusted to the data set (Isaac and Ruffino, 1996; Penna et al., 2005; Petrere, 1983). This procedure does not account for the likely uncertainty related to the structure of the model and implicitly assumes the existence of one "true" model. This assumption is unrealistic and is not justified by philosophy or mathematics (Buckland et al., 1997; Burnham and Anderson, 2002; Chatfield, 1995).

Computer-intensive methods allow a large number of models to be considered, and data-dependent specification searches have become common procedure in biology (Manly, 2007; Roff, 2006). Akaike's information criterion (AIC) for model selection is relatively recent and uses a Kullback-Leibler inform (or K-L distance) as a fundamental, conceptual measure of the relative distance of a given model from full reality (Burnham and Anderson, 2002). Although the use of AIC for model selection would be a better approach than arbitrarily picking a model, data often supports more than one model, reinforcing that uncertainty in model selection cannot be ignored (Burnham and Anderson, 2002; Katsanevakis, 2006). In practice, if model selection uncertainty is ignored, precision is often overestimated, and predictions are less accurate than expected (Burnham and Anderson, 2002). Thus, rather than making inferences from a unique model estimated to be best from a set of models, robust inferences can be made from several models or on the entire model set via model averaging (Burnham and Anderson, 2002).

The tambaqui is one of the key species among Amazonian fish of commercial value. However, some aspects of the biology of growth of wild animals in its natural environment are not fully understood. In this study, statistics of model selection and multimodel inference (MMI), based on information theory approach, are applied for length-age data, aiming to obtain a more robust estimation of the parameters of growth of juveniles and young adults in tambaqui stocks living in floodplain lakes. Growth parameters and inferences will help to better understand the effect of the fishery fleet, acting specifically on floodplain lakes, and the present diminution of the mean size of landed tambaquis.

\section{Material and Methods}

Fish were sampled from floodplain lakes at the Reserva de Desenvolvimento Sustentável Mamirauá (RDSM), located in the confluence of the Solimões and Japurá Rivers in Amazonas state, Brazil (see Figure 1), during low water seasons from 1993 to 1995. Fish are confined to lakes during the dry season and are thus isolated from the main river channel and other surrounding water bodies. Each lake was sampled once a year with an encircling gillnet that was $120 \mathrm{~m}$ long, $9 \mathrm{~m}$ high and $0.14 \mathrm{~m}$ between opposite knots.

Length was measured as snout to the extremity of the mesial ray of the caudal fin (fork length) and a sample of scales was taken from the region below the pectoral fin from each fish caught, before its liberation in the original lake. Age was determined by ring counting, as described in Costa et al. (1999). From the total sample of captured fish, a stratified subsample of five tambaquis for each 2 -cm length class was taken for the readings of growth rings. The age validation method employed was based on a mark-recapture experiment of wild fish. Scales were removed at the time of tagging and release of wild fish. The removed scale was used to estimate the age at tagging, and the time at liberty added to estimate the absolute age of the recaptured fishes (unpublished data). The data of mean length estimated for each age class were used to model the growth of C. macropomum. This approach was used in all previous studies on the growth of this species (Petrere, 1983; Isaac and Ruffino, 1986; Penna et al., 2005) and was adopted here to ensure comparability of results.

\subsection{Set of candidate models}

Four models commonly used for estimating parameters of fish growth were evaluated (Equations 1-4):

Logistic (Ricker, 1975): $1_{\mathrm{t}}=\mathrm{L}_{\infty}\left(1+\mathrm{e}^{-\mathrm{k}\left(\mathrm{t}-\mathrm{t}_{0}\right)}\right)^{-1}$ 


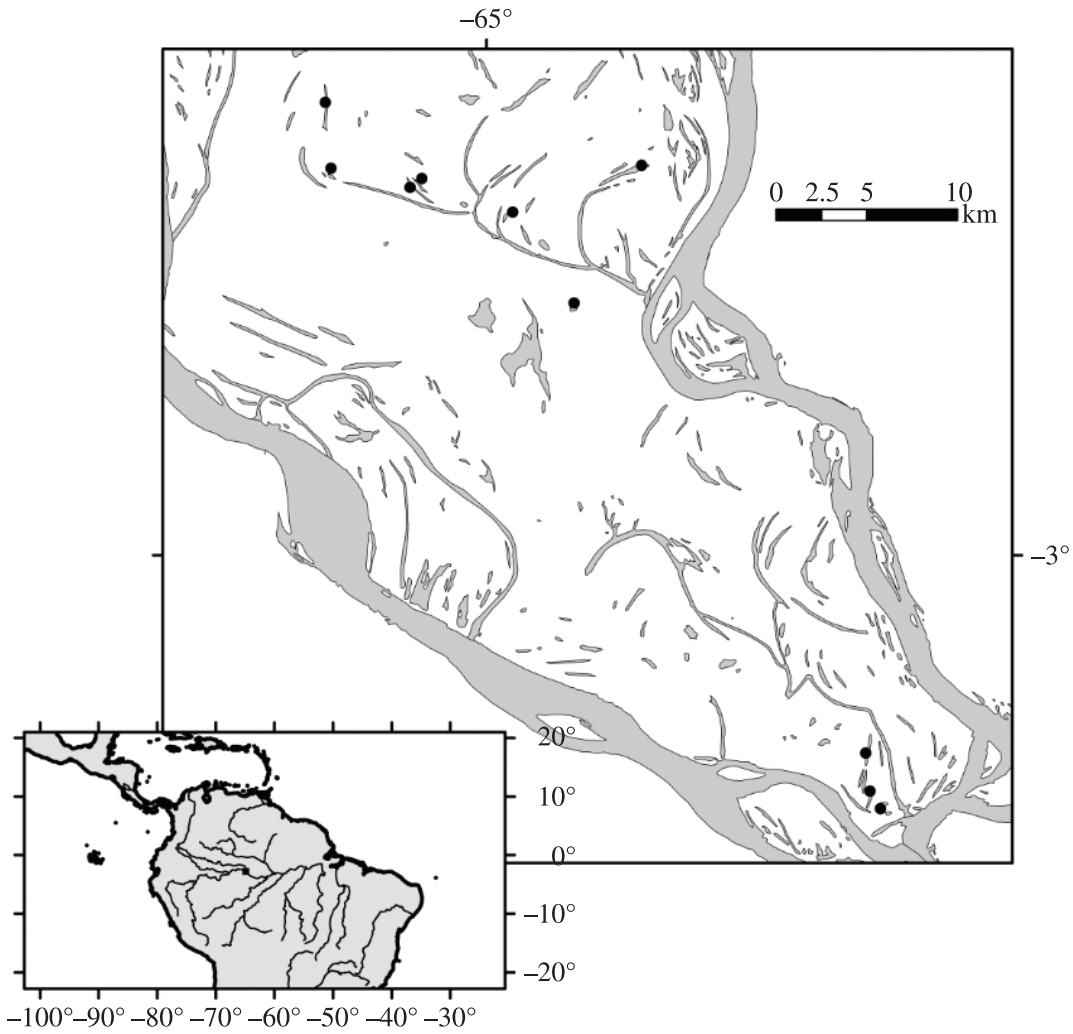

Figure 1. Study region and sampled lakes (black circles).

Gompertz (1825): $1_{\mathrm{t}}=\mathrm{L}_{\infty} \exp \left(-\mathrm{e}^{-\mathrm{k}\left(\mathrm{t}-\mathrm{t}_{0}\right)}\right)$

Von Bertalanffy (1938): $1_{t}=L_{\infty}\left(1-e^{-k\left(t-t_{0}\right)}\right)$

Schnute-Richards (1990): $1_{t}=L_{\infty}\left(1+\alpha \mathrm{e}^{-k t^{1}}\right)^{1 / b}$

These four candidate models, respectively $g_{I}: g_{1}-g_{4}$, were adjusted to the length-age data obtained via scale readings of tambaquis captured in the floodplain lakes. Equation 4 is a special case of the general Schnute-Richards model of fish growth, and it is equivalent to the generalised Schnute growth model with four parameters (Haddon, 2001; Quinn II and Deriso, 1999; Schnute and Richards, 1990). This last parameterisation corresponds to the logistic, von Bertalanffy, and Gompertz models when the parameter $b$ is respectively: $-1,1$ and $\approx 0.01$. Equation 4 was used as a substitute of the original model of Schnute (1981) because it gives a direct estimation of asymptotic length and because the data set does not support the adjustment of a more parameterised equation.

\subsection{Modelling the growth of tambaqui}

All the models $g_{I}(i=1, \ldots, R)$ were adjusted to the data by non-linear weighted regressions using the sample size of each length class as weight. This strategy makes an efficient use of small data sets and yields better estimates of parameters and respective confidence intervals. Iterations were conducted using the algorithm Levenberg-Marquardt, available in the SPSS software, v.15.0 (SPSS 2006), assuming an additive error structure. The best model among the candidate models was selected using Akaike's Information Criterion adjusted for small sample sizes or AIC $_{c}$ (Burnham and Anderson, 2002; Hurvich and Tsai, 1989; Shono, 2000). The AIC is based on information theory and has been computed from least squares regression statistic as (Burnham and Anderson, 2002) (Equation 5):

$\mathrm{AIC}_{\mathrm{c}}=\mathrm{n} \log \left(\hat{\sigma}^{2}\right)+2 \mathrm{k}+\frac{2 \mathrm{k}(\mathrm{k}+1)}{\mathrm{n}-\mathrm{k}-1}$

where $\hat{\sigma}^{2}=\mathrm{RSS} / \mathrm{n}, \mathrm{RSS}$ is the residual sum of squares for a particular candidate model, $n$ is the sample size and $k$ is the total number of estimated regression parameters including $\sigma^{2}$ (number of parameters in the model equation plus one). Normally distributed deviations with constant variance were assumed. The models were ranked and compared using $\triangle \mathrm{AIC}_{\mathrm{c}}$ and Akaike weights (Burnham and Anderson, 2002) The $\Delta \mathrm{AIC}_{\mathrm{c}}$ for each model $i$ was calculated as (Equation 6):

$\Delta \mathrm{AIC}_{\mathrm{c}_{\mathrm{i}}}=\mathrm{AIC}_{\mathrm{c}_{\mathrm{i}}}-\mathrm{AIC}_{\mathrm{c}_{\text {min }}}$

The values of $\Delta \mathrm{AIC}$ help to compare the relative distance between the most parsimonious model, which represents the best compromise between accuracy and precision $\left(\mathrm{AIC}_{\mathrm{c}_{\text {. }}}\right)$, and each other candidate model $\left(\mathrm{AIC}_{\mathrm{c}_{\mathrm{i}}}\right)$. The fit of candidate 
models is considered essentially equivalent when $\triangle \mathrm{AIC}$ is smaller than two (Burnham and Anderson, 2002). The Akaike weight $\left(w_{I}\right)$ is used to quantify the plausibility of each model $i$, given the set of a priori candidate models and the data. The most plausible candidate model has the greatest $w_{I}$. The $w_{I}$ derived from the differences between $\mathrm{AIC}_{\mathrm{c}}$ values was computed as (Burnham and Anderson, 2002) (Equation 7):

$\mathrm{w}_{\mathrm{i}}=\frac{\exp \left(-\frac{1}{2} \Delta_{\mathrm{i}}\right)}{\sum_{\mathrm{r}=1}^{\mathrm{R}} \exp \left(-\frac{1}{2} \Delta_{\mathrm{r}}\right)}$

where $\Delta_{I}$ is the $\Delta \mathrm{AIC}_{\mathrm{c}}$, and $R$ is the number of candidate models used in the analysis. The Akaike weights given for each model are interpreted as a measure of evidence of the "best'" one within the set of candidate models (Akaike, 1983; Buckland et al., 1997; Burnham and Anderson 2002). However, if no single model is clearly superior $\left(w_{I}<0.9\right)$ to the others in the set, then model-averaged parameter estimates using Akaike weights is recommended (Burnham and Anderson, 2002). The model-average was computed by averaging the predicted response variable $L(t)$ across models, using the corresponding $w_{I}^{\prime}$ s as weights (Burnham and Anderson, 2002; Katsanevakis, 2006). The modelaveraged asymptotic length was calculated as (Burnham and Anderson, 2002; Katsanevakis, 2006; Katsanevakis and Maravelias, 2008) (Equation 8):

$\overline{\mathrm{L}}_{\infty}=\sum_{\mathrm{i}=1}^{\mathrm{R}} \mathrm{w}_{\mathrm{i}} \hat{\mathrm{L}}_{\infty \mathrm{i}}$,

where $\hat{\mathrm{L}}_{\infty \mathrm{i}}$ denotes estimated asymptotic length for each model $g_{I}, i=1, . ., R$, and asymptotic $95 \%$ CI estimated as $\hat{\mathrm{L}}_{\infty \mathrm{i}} \pm \mathrm{t}_{\text {d.f., }, 0,975} \mathrm{~S} . \mathrm{E}\left(\hat{\mathrm{L}}_{\infty \mathrm{i}}\right)$ The unconditional standard error of $\overline{\mathrm{L}}_{\infty}$ was estimated as following (Burnham and Anderson, 2002) (Equation 9):

$$
\text { S.E. }\left(\overline{\mathrm{L}}_{\infty}\right)=\sum_{\mathrm{i}=1}^{\mathrm{R}} \mathrm{w}_{\mathrm{i}} \sqrt{\operatorname{var}\left(\hat{\mathrm{L}}_{\infty \mathrm{i}} \mid \mathrm{g}_{\mathrm{i}}\right)+\left(\hat{\mathrm{L}}_{\infty \mathrm{i}}-\overline{\mathrm{L}}_{\infty}\right)^{2}}
$$

where $\operatorname{var}\left(\hat{\mathrm{L}}_{\infty \mathrm{i}} \mid \mathrm{g}_{\mathrm{i}}\right)$ is the variance of the estimated asymptotic length, conditional on the model $g_{I}$ (Buckland et al., 1997; Burnham and Anderson, 2002). The asymptotic $L_{\infty}$ was the only parameter chosen to represent the averaged-model in this study, because the other parameters, $k$ e $t$, do not have the same meaning across models evaluated (Katsanevakis, 2006; Quinn II and Deriso, 1999; Ricker 1975; Schnute and Richards, 1990).

\section{Results}

\subsection{Key mean length-age}

A total of 3,524 tambaquis were caught within the ten lakes of the RDSM. All fish had a fork length smaller than $63 \mathrm{~cm}$, and only $3 \%$ or captured fish had length equal or larger than the minimum size allowed by Brazilian legislation
$(55 \mathrm{~cm})$. The subsample taken to scale readings included 526 individuals, and data analyses indicated that tambaquis in the study region stay confined within floodplain lakes for approximately 5-6 years (as shown in Table 1).

\subsection{Comparing growth models}

Based on values for $\Delta_{I}$ it is possible to conclude that both the logistic $\left(\Delta_{I}=0.00\right)$ and Gompertz $\left(\Delta_{I}=1.12\right)$ models are equally well supported by the dataset available for C. macropomum (as shown in Table 2). However, according to Akaike weights, the Logistic model is 1.80 times better supported than the Gompertz model. The von Bertalanffy model was also supported by the data, with a weight of evidence of $17.60 \%$. However, the estimation of the asymptotic length $L$ and the corresponding asymptotic 95\% confidence interval are evidence that the von Bertalanffy model underestimates the precision for the available dataset. The Schnute-Richards model had essentially no support in the data, and overestimated precision (see Table 2).

The logistic model was not a "clear winner" $\left(w_{I}<90 \%\right)$. Thus, it is too risky to make inferences based uniquely on this model. However, estimating the average model using the set of candidate models could lead to an underestimation of the precision of model-averaged asymptotic length (see Table 2). The most robust estimate of $L_{\infty}$ was obtained by excluding the von Bertalanffy and Schnute-Richards models, which had little or no support from the data from the final average estimate (as shown in Table 3).

The projection of the growth curve of Colossoma macropomum, according to the average model prediction, suggests that this species in nature would take approximately 25 years to reach a mean $L_{\infty}$ of approximately $90 \mathrm{~cm}$ of fork length (see Figure 2).

\section{Discussion}

The use of the Akaike Information Criterion (AIC) for selection of the best fit model revealed a high degree of uncertainty that cannot be ignored. This uncertainty could have serious implications for parameter estimation and comparison of parameters among different populations and consequently for delineation of specific management strategies (Katsanevakis, 2006; Katsanevakis and Maravelias, 2008).

Table 1. Mean length by age for tambaquis caught within floodplain lakes at the MSDR, between 1993 and 1995 $(\mathrm{n}=526)$.

\begin{tabular}{ccc}
\hline $\begin{array}{c}\text { Relative age } \\
\text { (year) }\end{array}$ & $\begin{array}{c}\text { Mean length } \\
(\mathbf{c m})\end{array}$ & $\begin{array}{c}\text { Number of } \\
\text { individuals }\end{array}$ \\
\hline 0 & 26.75 & 2 \\
1 & 32.42 & 40 \\
2 & 39.47 & 157 \\
3 & 46.59 & 152 \\
4 & 54.16 & 115 \\
5 & 60.15 & 58 \\
6 & 62.60 & 2 \\
\hline
\end{tabular}


Table 2. Summary of the modelling of tambaqui (Colossoma macropomum) growth by using data of length-age obtained by reading growth rings in scales of fish captured within floodplain lakes.

\begin{tabular}{|c|c|c|c|c|c|c|c|c|}
\hline \multirow{2}{*}{ Models } & \multirow{2}{*}{$\boldsymbol{k}$} & \multirow{2}{*}{$\mathrm{AIC}_{\mathrm{c}}$} & \multirow{2}{*}{$\Delta_{i}$} & \multirow{2}{*}{$w_{i}(\%)$} & \multicolumn{4}{|c|}{$L_{\infty(\mathrm{cm})}$} \\
\hline & & & & & Estimate & SE & LCI $(95 \%)$ & UCI $(95 \%)$ \\
\hline$g_{1}:$ Logistic & 4 & 33.37 & 0.00 & 52.44 & 83.51 & 4.97 & 69.70 & 97.32 \\
\hline$g_{2}:$ Gompertz & 4 & 34.49 & 1.12 & 29.95 & 102.98 & 13.56 & 65.34 & 140.62 \\
\hline$g_{3}:$ von Bertalanffy & 4 & 35.55 & 2.18 & 17.61 & 244.27 & 206.70 & - & 818.15 \\
\hline$g_{4}:$ Schnute-Richards & 5 & 71.77 & 38.40 & 0.00 & 66.29 & 2.65 & 57.84 & 74.73 \\
\hline Model-averaged & & & & & 117.46 & 66.71 & - & 302.91 \\
\hline
\end{tabular}

where $k$ is the number of estimated parameters in the model; $\mathrm{AIC}_{\mathrm{c}}$, is the second order Akaike information criterion; $\Delta_{\mathrm{i}}$, is the difference between the $\mathrm{AIC}_{\mathrm{c}}$ of each model and the model with the lowest $\mathrm{AIC}_{\mathrm{c}}$ value; $\mathrm{w}_{\mathrm{i}}$, is the Akaike weigth for the model; $\mathrm{L}_{\infty}$, is the asymptotic length; SE, estimated standard error; - negative value; LCI, lower confidence interval; UCI, upper confidence interval.

Table 3. Result of modelling growth for tambaqui (Colossoma macropomum) after excluding the Von Bertalanffy and Schnute-Richard models

\begin{tabular}{|c|c|c|c|c|c|c|c|c|}
\hline \multirow{2}{*}{ Models } & \multirow{2}{*}{$\boldsymbol{k}$} & \multirow{2}{*}{$\mathrm{AIC}_{\mathrm{c}}$} & \multirow{2}{*}{$\Delta_{i}$} & \multirow{2}{*}{$w_{i}(\%)$} & \multicolumn{4}{|c|}{$L_{\infty(\mathrm{cm})}$} \\
\hline & & & & & Estimate & S.E & LCI $(95 \%)$ & UCI $(95 \%)$ \\
\hline$g_{1}:$ Logistic & 4 & 33.37 & 0.00 & 63.64 & 83.51 & 4.97 & 69.70 & 97.32 \\
\hline$g_{2}:$ Gompertz & 4 & 34.49 & 1.12 & 36.36 & 102.98 & 13.56 & 65.34 & 140.62 \\
\hline Model-averaged & & & & & 90.36 & 11.87 & 57.36 & 123.36 \\
\hline
\end{tabular}

where $k$ is the number of estimated parameters in the model; $\mathrm{AIC}_{\mathrm{c}}$, is the second order Akaike information criterion; $\Delta_{\mathrm{i}}$, is the difference between the $\mathrm{AIC}_{\mathrm{c}}$ of each model and the model with the lowest $\mathrm{AIC}_{\mathrm{c}}$ value; $\mathrm{w}_{\mathrm{i}}$, is the Akaike weigth for the model; $\mathrm{L}_{\infty}$, is the asymptotic length; SE, estimated standard error; - negative value; LCI, lower confidence interval; UCI, upper confidence interval.

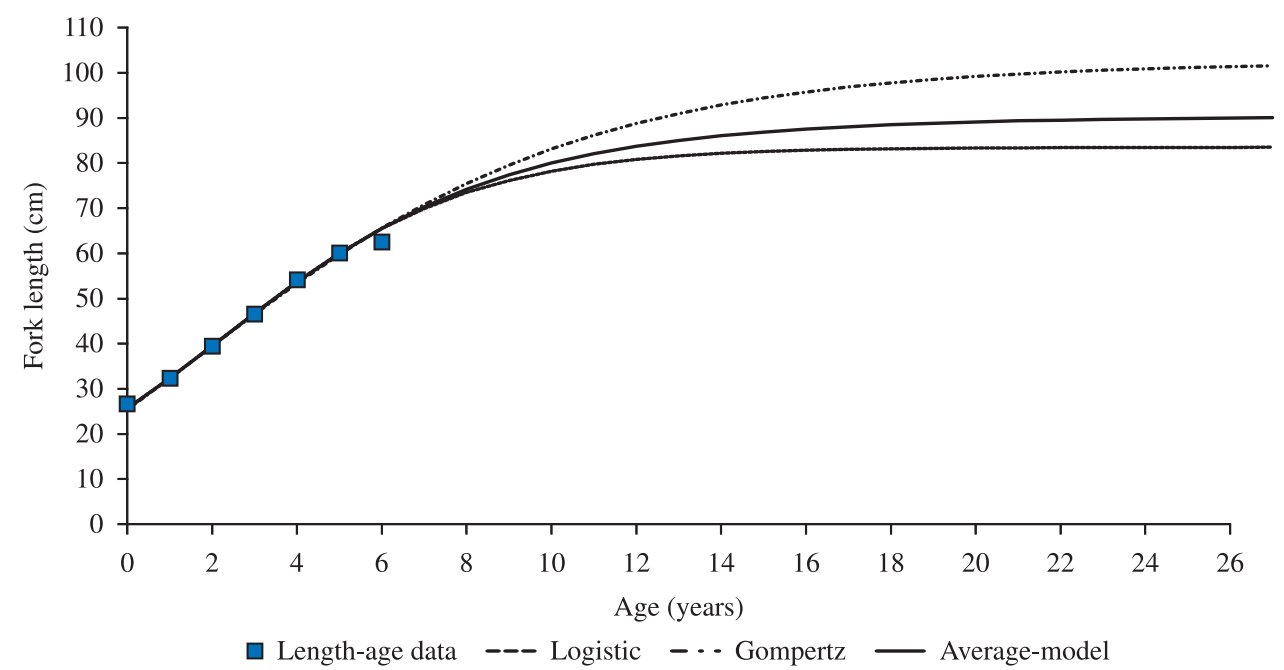

Figure 2. Growth curves for the tambaqui, including the Logistic, Gompertz and the averaged-model.

For the present data set, the information theory method reinforced the importance of multimodel inference, which allowed estimating a growth parameter by model-averaging, yet the dataset has supported more than one model between the applied candidate models. In this situation, using only one model in the set could result in estimating growth parameters with low precision or accuracy.
The a priori use of the von Bertalanffy equation has been questioned by many authors (Knight, 1968; Roff,1980; Schnute, 1981). (Katsanevakis and Maravelias, 2008) applied the AIC to select from four different models adjusted to 133 length-age datasets for 82 fish species and concluded that the von Bertalanffy equation was not the best model for $65.4 \%$ of them. The von Bertalanffy equation tends to 
be better suited to describe the growth of a species when adjusted to a dataset composed by many older animals, which exhibit a maximum asymptotic length (Haddon, 2001; Roff, 1980). For tambaquis proceeding from the Solimões-Amazonas rivers and its tributaries, the von Bertalanffy adjustment to age-length of adult individuals (length $>55 \mathrm{~cm}$ ) has revealed an asymptotic pattern of growth (Petrere, 1983).

It is important to emphasize that the aim of information theory is not to simply model the data, but to recover the information contained (Buckland et al., 1997; Burnham and Anderson, 2002). In this sense, model selection is not only dependent on the pattern of growth of each species, but also on the quality and characteristics of the dataset and the quantity of information that it contains (Katsanevakis, 2006; Katsanevakis and Maravelias, 2008). Therefore, if a species presents an asymptotic growth but adult individuals are absent from the dataset, the von Bertalanffy model would not be well supported because the von Bertalanffy equation has the assumption of asymptotic growth. This can partially explain the poor performance of the von Bertalanffy model in this study, where the dataset was composed primarily by young tambaquis and presented a reduced number of adults. This characteristic forced the von Bertalanffy model to obtain the $L_{\infty}$ parameter through extrapolation, and the result was considered largely overestimated $\left(L_{\infty} \approx 244 \mathrm{~cm}\right)$ because is above all estimates of this parameter obtained in the literature and considered biologically plausible for this species (see Table 4).

However, the poor fit of the von Bertalanffy model to this species is not merely related to the profile of the present dataset. Even the dataset used by Petrere (1983), which was predominantly composed of adults, presented a low performance when the von Bertalanffy model was adjusted. Petrere (1983) presented a plausible $L_{\infty}$ because this author did not estimate this parameter by modelling, but has fixed it as $107.3 \mathrm{~cm}$, based on the largest tambaqui found in nature. As his data matrices are available (Tables III e IV in Petrere, 1983), it was possible to use that dataset to adjust the von Bertalanffy model and to estimate the $L_{\infty}$ parameter and its respective confidence interval (as shown in Table 4). The results have shown high uncertainty associated to the von Bertalanffy model adjusted to that dataset: the $95 \%$ CI for $L_{\infty}$ obtained was wider than that obtained by the averaged-model estimated in this study.

All data analyses have the objective of making inferences that can be appropriately applied to the population (Anderson, 2007; Burnham and Anderson, 2002). The upper limit obtained by the Schnute-Richards model for the $L_{\infty}$ was $74.73 \mathrm{~cm}$, which clearly does not reflect what is found in nature. Despite their absence from our dataset, tambaquis with lengths equal or larger than $80 \mathrm{~cm}$ are still commonly caught outside várzea lakes (Costa et al., 1999). Therefore, when data adjustment is maximised in the general SchnuteRichards model, it is detrimental to the generalisation of parameter estimation. In this case, the $\mathrm{AIC}_{\mathrm{c}}$ reflected the "penalty" applied to the Schnute-Richards model for being a more parameterised model, which was not supported by the present dataset.

For the middle Solimões River population of tambaquis, the averaged-model calculated by a weighted mean of the predicted response variable $L(t)$ using the Logistic and Gompertz models resulted in a plausible estimate of the $L_{\infty}$ parameter. In the model selection context, when none of the models is clearly superior, the use of the averaged model is the best strategy (Buckland et al., 1997). Quantification of the uncertainty associated with $L_{\infty}$, obtained by calculating the confidence intervals around the estimated parameter has revealed that there are no significant differences between the prediction of $L_{\infty}$ obtained in this study by model-averaging and the predictions for this parameter found in the literature, yet all previous estimates for $L_{\infty}$ are within the $95 \%$ confidence interval (as shown in Table 4). In this study, the use of the $\mathrm{AIC}_{\mathrm{c}}$ reinforced the importance of considering the uncertainty in model selection for the estimation of growth parameters for freshwater Amazonian fish. Moreover, more robust parameter estimation can be obtained when the model-averaging procedure is based on models with strong data support.

Management of tambaqui fisheries in the Central Amazon is a challenge because of heterogeneity in exploitation, with commercial and subsistence fishermen using multi gear equipment and fishing along the large extension of

Table 4. $\mathrm{L}_{\infty}$ estimates for Colossoma macropomum by using different data sets.

\begin{tabular}{lccccc}
\hline \multicolumn{1}{c}{ Author } & Data type & $\mathbf{L}_{\infty}(\mathbf{c m})$ & SE & LCI (95\%) & UCI (95\%) \\
\hline Petrere (1983) & LF & $107.3(\mathrm{TL})$ & - & - & - \\
Petrere (1983) & LF & $103.7(\mathrm{TL}) *$ & 24.97 & 42.04 & 164.22 \\
Isaac and Ruffino (1996) & LF & $121.20(\mathrm{TL})$ & - & - & - \\
Isaac and Ruffino (1996) & LF & $118.50(\mathrm{TL})$ & - & - & - \\
Costa et al. (1999) & LF & $107.40(\mathrm{FL})$ & - & - & - \\
Penna et al. (2005) & RCS & $100.39(\mathrm{SL})$ & - & - & - \\
Penna et al. (2005) & RCS & $85.125(\mathrm{SL})$ & - & - & 123.36 \\
This study & RCS & $90.36(\mathrm{FL})$ & 11.87 & 57.36 & - \\
\hline
\end{tabular}

*Estimate obtained by a non-linear adjustment of Von Bertalanffy model on original data from Petrere (1983), by minimising RSS using a Gauss-Newton algorithm (LF = Length Frequency; RCS = Reading of Calcified Structures, TL = Total Length, FL $=$ Furcal Length, SL $=$ Standard Length, LCI $=$ Lower Confidence Interval, UCI $=$ Upper Confidence Interval). 
the main rivers and lakes. Profound knowledge of the life cycle of the exploited species is required for management of such resources. This study reinforces the importance of restricting the fisheries within floodplain lakes as the stock in these environments is mostly composed of juvenile and young adult individuals.

Acknowledgements - We thank the MAMIRAUÁ Project, ODA, WWF, WCS, CNPq, INPA, and MPEG for financial and logistical support. LRF Costa acknowledges the GEOMA Project (Biodiversity component) and CNPq for the grant received (Processo no. 372134/2010-6). The authors acknowledges fieldwork help and friendship from Sigueru Esashica and would like to dedicate this paper to his memory. We also thank an anonymous referee for insightful comments on the earlier version of the manuscript.

\section{References}

AKAIKE, H., 1983. Information measures and model selection. International Statistical Institute, vol. 44, p. 277-291.

ANDERSON, DR., 2007. Model based inference in the life sciences - a primer on evidence. New York: Springer. $184 \mathrm{p}$.

ARAÚJO-LIMA, CARM. and GOULDING, M., 1997. So Fruitful a Fish - Ecology, Conservation, and Aquaculture of the Amazon's Tambaqui. New York: Columbia University Press. 191 p.

BARTHEM, RB. and GOULDING, M., 2007. An unexpected ecosystem: the Amazon revealed by the fisheries. Lima: Grafica Biblos, 2007. 241 p.

BUCKLAND, ST., BURNHAM, KP. and AUGUSTIN, NH., 1997. Model selection: an integral part of inference. Biometrics, vol. 53, p. 603-618. http://dx.doi.org/10.2307/2533961

BURNHAM, KP. and ANDERSON, DR., 2002. Model selection and multimodel inference: a practical information-theoretic approach. New York: Springer. 488 p.

CHATFIELD, C., 1995. Model uncertainty, data mining and statistical inference. Journal of the Royal Statistical Society, vol. 158, no. 3, p. 419-466. http://dx.doi.org/10.2307/2983440

COSTA, LRF., BARTHEM, RB. and BITTENCOURT, MM., 2001. A Pesca do tambaqui, Colossoma macropomum, com enfoque na área do médio Solimões, Amazonas, Brasil. Acta Amazônica, vol. 31, no. 3, p. 449-467.

COSTA, LRF., BARTHEM, RB. and VILLACORTA-CORREA, MA., 1999. Manejo da pesca do tambaqui nos lagos de várzea da Estação Ecológica Mamirauá. In QUEIROZ, HL. and CRAMPTON, WGR. (Eds.). Estratégias para manejo de recursos pesqueiros em Mamirauá. Brasília: MCT/CNPq/SCM. p. 142-158.

GOULDING, M. and CARVALHO, ML., 1982. Life history and management of the tambaqui (Colossoma macropomum, Characidae): an important amazonian food fish. Revista Brasileira de Zoologia, vol. 1, no. 2, p. 107-133.

HADDON, M., 2001. Modelling and quantitative methods in fisheries. Boca Raton: Chapman \& Hall/CRC. 406 p.

HURVICH, CM. and TSAI, CL., 1989. Regression and time series model selection in small samples. Biometrika, vol. 76, p. 297-307. http://dx.doi.org/10.1093/biomet/76.2.297

ISAAC, VJ. and RUFFINO, ML., 1996. Population dynamics of tambaqui, Colossoma macropomum Cuvier, in the lower Amazon,
Brazil. Fisheries Management and Ecology, vol. 3, p. 315-333. http://dx.doi.org/10.1046/j.1365-2400.1996.d01-154.x

KATSANEVAKIS, S., 2006. Modelling fish growth: model selection, multi-model inference and model selection uncertainty. Fisheries Research, vol. 81, p. 229-235. http://dx.doi.org/10.1016/j. fishres.2006.07.002

KATSANEVAKIS, S. and MARAVELIAS, CD., 2008. Modelling fish growth: multi-model inference as a better alternative to a priori using von Bertalanffy equation. Fish and Fisheries, vol. 9, p. 1-10. http://dx.doi.org/10.1111/j.1467-2979.2008.00279.x

KNIGHT, W., 1968. Asymptotic growth: an example of nonsense disguised as mathematics. Journal of Fisheries Research Board of Canada, vol. 25, p. 1303-1307. http://dx.doi.org/10.1139/f68-114

MANLY, BFJ., 2007. Randomization, Bootstrap and Monte Carlo Methods in Biology. Boca Raton: Chapman \& Hall/ CRC, 2007. $455 \mathrm{p}$

PENNA, MAH., VILLACORTA-CORREAA, MA., WALTER, T. and PETRERE-JUNIOR, M., 2005. Growth of the tambaqui Colossoma macropomum (Cuvier) (Characiformes: Characidae): which is the Best model? Brazilian Journal of Biology, vol. 65, no. 1, p. 129-139. PMid:16025912. http://dx.doi.org/10.1590/ S1519-69842005000100017

PETRERE, MJ., 1983. Yield per recruit of the tambaqui, Colossoma macropomum Cuvier, in the Amazonas State, Brazil. Journal of Fish Biology, vol. 22, p. 133-144. http://dx.doi. org/10.1111/j.1095-8649.1983.tb04733.x

QUINN II, TJ. and DERISO, RB., 1999. Quantitative Fish Dynamics. edited by WM. GETZ. New York: Oxford University Press. 542 p.

RICKER, WE., 1975. Computation and Interpretation of Biological Statistics of Fish Populations. Bulletin Fisheries Research Board of Canada, vol. 191, p. 1-382.

ROFF, DA., 1980. A motion to retire the von Bertalanffy function. Canadian Journal of Fisheries and Aquatic Sciences, vol. 37, p. 127-129. http://dx.doi.org/10.1139/f80-016

-, 2006. Introduction to Computer-Intensive Methods of Data Analysis in Biology. New York: Cambridge University Press. 368 p.

SANTOS, MCF., RUFFINO, ML. and FARIAS, IP. 2007. High levels of genetic variability and panmixia of the tambaqui Colossoma macropomum (Cuvier, 1816) in the main channel of the Amazon River. Journal of Fish Biology, vol. 71, Supplement A, p. 33-44.

SCHNUTE, J., 1981. A versatile growth model with statistically stable parameters. Canadian Journal of Fisheries and Aquatic Sciences, vol. 38, p. 1128-1140. http://dx.doi.org/10.1139/f81-153

SCHNUTE, JT. and RICHARDS, LJ., 1990. A unified approach to the analysis of fish growth, maturity, and survivorship data. Canadian Journal of Fisheries and Aquatic Sciences, vol. 47, p. 24-40. http://dx.doi.org/10.1139/f90-003

SHONO, H., 2000. Efficiency of the finite correction of Akaike's information criteria. Fisheries Science, vol. 66, p. 608-610. http:// dx.doi.org/10.1046/j.1444-2906.2000.00095.x

Statistical Package for the Social Sciences - SPSS, 2006. SPSS for Windows Release. version for version 15.0. Chicago: SPSS Inc. 